\title{
A birthday party with real rockets
}

\section{Bulgaria is celebrating 1,300 years of nationhood next year, and scientific events are among the festivities. But as Vera Rich reports, the best birthday present the country could have would be a pollution-free water supply}

LATER this month, Bulgaria will hold its second national conference on molecular biology - the first scientific event of the jubilee.

Dedicating a scientific congress to an event in the remote past may seem novel to western eyes, but it is merely one of a whole series of scientific events associated with the anniversary. In spite of its relatively small size and low science budget (about $1.3 \%$ of the GNP) Bulgaria is doing work at an international level in a number of fields, molecular biology included.

According to Dr Rumen Tsanev, of the Institute of Molecular Biology of the Bulgarian Academy of Sciences, work in molecular biology began some 10 years ago - before the Soviet decrees of 1974 which assigned priority to catching up in molecular biology and genetics. Lysenkoism, however, never really took hold in Bulgaria; there was some theoretical discussion of it in the 1950s but this was quickly over and, said Professor Tsanev, there was no persecution of people who did not accept it.

Bulgarian work on molecular biology has included: the discovery that the nucleosome consists of two sub-units; the formulation of mathematical models of cell differentiation; study of the role of histones in DNA transcription; and, most recently, two-dimensional electrophoresis studies of differences in the primary structure of nucleosomes. As for genetic engineering, "We feel it can only be developed as part of general molecular biology", Tsanev explained. "We started only last year, and at present we are simply trying to introduce methods of handling and mastering the techniques". Preparing too for genetic engineering, is Dr Basil Staikov of Bulgaria's unique "Rose Institute" at Kazanlak, a research station devoted to every aspect (from biochemistry to the mechanics of harvesting) of the Kasanlak roses whose essential oils play so significant a role in the Bulgarian economy. For the moment, however, Dr Staikov explained, Kazanlak has not the equipment for genetic engineering, and new varieties are still obtained by traditional cross-breeding methods; $y$-irradiation experiments begun some four years ago, said Staikov, have so far given no definite results, although the general indications seem "promising".

Bulgaria is extremely proud of the scientific traditions it has established during the last century or so. The Academy of Sciences was founded in 1869. Bulgarian

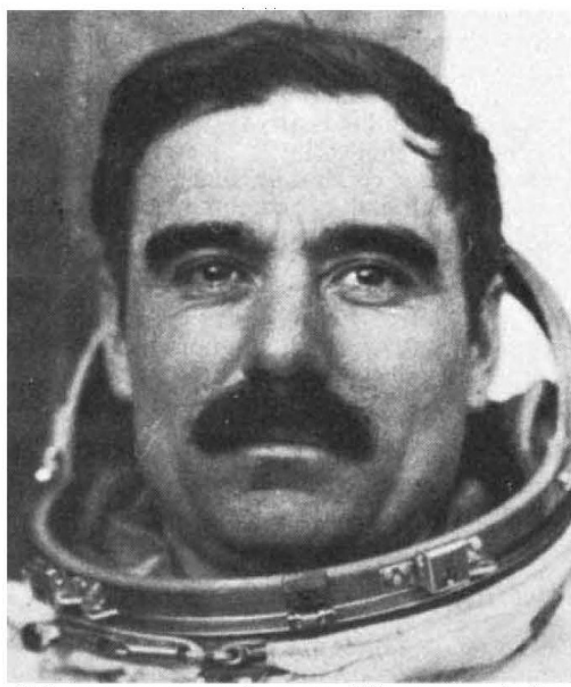

Citizen-cosmonaut Ivanov His space mission failed last year - but the scientific side of the programme was carried through.

scientists have been particularly active in solid state physics; but last year, according to $\mathrm{Dr}$ Milko Borisov, Director of the Academy's Joint Centre for Physics, the best results in Bulgarian physics came from work on liquid crystals, dielectric and flexielectric properties. Specialists from the Centre are cooperating with Polish and Italian teams on an "Atlas of liquid crystals" to be published by the Bulgarian Academy, probably in 1981 .

International projects, naturally, cannot be dedicated to the Bulgarian jubilee. Nor, it seems, can the new astronomical observatory at Roehen, with its $200 \mathrm{~cm}$ hyperbolic mirror with a Richey-ChretienCoudé focus system. Much of the optical equipment came from Karl Zeiss (JENA) and when the observatory is formally opened later this year, it seems likely that it will be dedicated to DDR-Bulgarian friendship.

However, Bulgarian statehood will be celebrated in astrophysics. A special satellite Bulgaria- 1300 will be launched by a Soviet rocket towards the end of the year. The experiments it will carry are, for the moment, a secret, but, according to $\mathrm{Dr}$ Kiril Serafimov, head of space research, Bulgaria is an active participant in all five sections of the "Interkosmos" programme - space physics, meteorology, communications, space biology/medicine, and remote geophysical sensing. Even before "Interkosmos" was set up as the official organisation for Comecon joint research, Bulgarian physicists assisted their Soviet colleagues in evaluating data from the "Elektron" probe - and later, from US satellites.

The Bulgarian public is still hopeful that their "space" celebrations might include the launch of a second Bulgarian cosmonaut, and with greater success than Georgi Ivanov, who with a Soviet crewmate, failed last year to link up with Salyut-6. But 20 of his scheduled experiments were carried out by the Soviet team on board including work with the Bulgarian Spektr-15 remote sensing camera (which weighs only $15.2 \mathrm{~kg}$ but has 15 channels), the casting of an aluminiumhydrogen foam, work on epitaxial surfaces and crystal growth, and electrophotomagnetic experiments on the aurora. Only the seven medical experiments scheduled for Ivanov had to be abandoned.

Perhaps the biggest scientific contribution to the jubilee will be the publication of Bulgaria's "Red Book" of endangered species. According to Professor Simeon Nedyalkov, of the Institute for the Coordination of Research for Environmental Conservation Bulgaria is, from a geobotanical point of view, a "melange" of boreal, mediterranean, pontic and Asia-minor species. Since the "technical revolution", especially around the country's new metallurgical plants, many species are threatened. There has been over-cutting of valuable timber; snowdrops have been depleted by the demands of the medical profession (they yield nivalin - an alkaloid used in the treatment of polio); and a well-intentioned attempt to step up trout production by introducing American varieties proved disastrous, for the newcomers failed to adapt to local plankton and became predators on the native trout.

Now, however, said Professor Nedyalkov, Bulgaria has a well established national monitoring system for all forms of air and water pollution, and in especially menaced areas, soil pollution also; and work is going forward on the resistance of plants to toxic elements.

Bulgaria's concern for the environment extends to the international level - not surprisingly, since its only sizeable river, the Danube, arrives too polluted even for irrigation. The existing Danube Commission covers only pollution from ships, and Bulgaria has been one of the most active of the riparian states in pressing for a Danube Convention to cover all aspects of monitoring and research into water quality and ecology. The preliminary text for a Convention has already been drafted and, said Dr Veselin Petrov of the Committee of Environmental Protection of the Council of Ministers, it is hoped that a final text will be signed this year. That would be the best 1300 th birthday present Bulgaria could receive from the up-stream Danube countries. 